\title{
Effect of injected heparin on platelet levels in man
}

\author{
M. G. DAVEY ${ }^{1}$ AND HARRY LANDER \\ From the Department of Medicine, University of Adelaide, \\ Adelaide, Australia
}

SYNOPSIS Platelets from six normal subjects were labelled with radiochromate and reinfused into their donors. Subsequently, the effect of intravenously injected heparin upon the levels of circulating platelets and platelet radioactivity was studied. Although reductions in platelet counts occurred in three subjects following single injections of 10,000 units, these changes were not reflected in the levels of circulating platelet radioactivity. It is concluded that the alterations in platelet counts observed were probably due to an effect of heparin in vitro. The experimental evidence that heparin induces thrombocytopenia in vivo, in man, is unconvincing.

The effect of injections of heparin on circulating platelet levels has long been controversial. In the 1940s a number of investigators demonstrated transient thrombocytopenia in dogs after intravenous heparin administration (Copley and Robb, 1942b; Fidlar and Jaques, 1948; Quick, Shanberge, and Stefanini, 1948), but the phenomenon was not observed in other experimental animals, e.g., mice, rabbits (Copley and Robb, 1942b; Quick et al., 1948) with the possible exception of hamsters (Copley, 1948). Then and since, its occurrence in man has been affirmed by some reports (Fidlar and Jaques, 1948; Gollub and Ulin, 1962) but denied by others (Quick et al., 1948; Borchgrevink, 1961; Salzman, 1963).

Circumstantial evidence against a thrombocytopenic effect of heparin in man is provided by reports that its administration prevents the thrombocytopenia associated with allergic reactions (Johannson, Lundberg, and Sjöberg, 1960) and with hypothermia (Wensel and Bigelow, 1959). Furthermore, heparin has been used in the treatment of bleeding diatheses due to intravascular coagulation and excessive fibrinolysis (Godal and Abildgaard, 1963; Verstraete, Amery, Vermylen, and Robyn, 1963; von Francken, Johannson, Olsson, and Zetterqvist, 1963; Verstraete, Vermylen, Vermylen, and Vandenbroucke, 1965) and in the management of cases of purpura fulminans (Hjort, Rapaport, and Jørgensen, 1964) and of purpura gangrenosa (Sharp, Harding, and Ellis, 1965). In a number of these instances, platelet counts increased during

${ }^{1}$ Present address: Red Cross Blood Transfusion Service, Perth, W. A., Australia

Received for publication 1 May 1967. heparin medication (Verstraete et al., 1963; Verstraete et al., 1965; Hjort et al., 1964; Sharp et al., 1965). In none did thrombocytopenia follow its administration.

Reductions of platelet counts have frequently been reported to follow heparinization and extracorporeal circulation for cardiac surgery (Björk, 1960; Bloom, 1961 ; Gans and Krivit, 1962; Moret, Feuardent, and Pattay, 1962; Salzman, 1963). These changes could be due to entry of platelet-poor blood to the circulation (Gans and Krivit, 1962; Moret et al., 1962; Salzman, 1963), to exposure of platelets to foreign surfaces, where heparin may even enhance their adhesion (Mustard, Murphy, Downie, and Rowsell, 1963), and to hypothermia (Wensel and Bigelow, 1959; Björk, 1960). In so complex a situation it would seem impossible to isolate an effect, if any, of heparin.

Summing up the evidence available Hartmann (1961) decided that there was good evidence for a thrombocytopenic effect of heparin in dogs, but that 'in man ..... the better evidence disclaims any appreciable effect'. More recently, however, Gollub (1964) has again strongly stated the opposite view, basing his case principally on one group of experiments (Gollub and Ulin, 1962). The present studies were undertaken in an attempt to verify these and to help resolve the question.

\section{MATERIALS AND METHODS}

SUBJECTS Six healthy male volunteers between the ages of 20 and 28 years were studied.

Platelet LABElling WITH RADIOChromate Platelets from each subject were isolated, labelled with radio- 
chromate as previously described (Davey and Lander, 1963), and reinfused into their donors for determination of their survival in vivo. The present studies were undertaken in each subject during a period between three and 36 hours after infusion, when blood and platelet radioactivity are sufficiently stable to serve as indicators of circulating platelet levels (Davey and Lander, 1964a, 1964b).

INJECTIONS were given and blood samples obtained through indwelling venous catheters ${ }^{1}$. The samples were collected into glass syringes lubricated with silicone fluid $^{2}$ and handled in polypropylene tubes ${ }^{3}$, using disodium ethylene-diamine-tetra-acetate (E.D.T.A.; $3 \%(\mathrm{w} / \mathrm{v})$ in $0.7 \%$ saline, one part to nine of blood) as anticoagulant.

PLATELET COUNTS were performed on all samples at the end of each experimental period by phase-contrast microscopy using $1 \%$ ammonium oxalate solution as diluent (Brecher and Cronkite, 1950).

RADIOACTIVITY DETERMINATIONS were performed on aliquots of whole blood and of isolated platelets, as described previously (Davey and Lander, 1963).

Clotting times (Lee White) were determined in untreated glass tubes at $37^{\circ} \mathrm{C}$. in duplicate.

DRUGS The following commercial preparations of drugs were used: Heparin (B.P.): two different preparations, one from Commonwealth Serum Laboratories, Melbourne, Australia, and the other from Boots Pure Drug Co., Ltd., Nottingham, England; both 5,000 units (50 mg.) per ml.

Protamine sulphate from Evans Medical [Ltd., Liverpool, England, as a $1 \%(w / v)$ isotonic solution. Hexadimethrine bromide (Polybrene), from Abbott Laboratories, Illinois, U.S.A., as a $1 \%(w / v)$ solution which was diluted with nine parts of physiological saline before intravenous administration.

\section{RESULTS}

CONTROL DETERMINATIONS Serial blood samples were obtained from resting untreated subjects over a period of three hours between three and 36 hours after infusion of the labelled platelets. At this time at least one-half of the total radiochromate activity in blood samples is associated with the platelets, and platelet radioactivity levels are most stable (Davey and Lander, 1964a). The platelet counts and whole blood and platelet radioactivity measurements in the samples obtained were compared statistically for each subject. Table I shows the findings in two such studies, each in a single subject.

The variances of repeated platelet counts in individual resting subjects were within the limits

\footnotetext{
${ }^{1}$ Bardic Intracath No. 1614. C. R. Bard and Co., Philadelphia, U.S.A. 'Dimethyl fluid No. 200/200. Dow Corning, Midland, Michigan, U.S.A.

'Medical and Scientific Equipment Co., London, England.
}

TABLE I

CONTROL DETERMINATIONS OF PLATELET COUNTS AND OF WHOLE BLOOD AND PLATELET RADIOCHROMATE ACTIVITY IN TWO SUBJECTS

$\begin{array}{lll}\text { Platelets } & \text { Whole Blood } & \text { Platelet } \\ \text { (per c. mm.) } & \text { Activity } & \text { Activity } \\ & \text { (c.p.s. per } & \text { (c.p.s. per } \\ & 10 \mathrm{ml} .) & 10 \mathrm{ml} \text {. blood }\end{array}$

Subject $A$ (between 3 and 5

hours after infusion)

No. of samples

Mean value

Coefficient of variation

Subject B (between 33 and

36 hours after infusion)

No. of samples

Mean value

Standard deviation \pm

Coefficient of variation

8
234,750
20,020
$8.5 \%$

$\begin{array}{rr}10 & 9 \\ 100 \cdot 15 & 51 \cdot 76 \\ 5.57 & 4 \cdot 15 \\ 5.6 \% & 8 \cdot 0 \% \\ & \\ 7 & 8 \\ 77 \cdot 50 & 38 \cdot 32 \\ 3.76 & 1 \cdot 21 \\ 4.9 \% & 3.2 \%\end{array}$

predicted for the method used (Brecher, Schneiderman, and Cronkite, 1953). The variances of radioactivity determinations were lower than those of platelet counts and, in general, variance of wholece blood radioactivity was less than that of plateleteo activity. Hence it was concluded that variationsin platelet levels would be most sensitively detecteds by measurements of whole blood radioactivity This conclusion has been verified by studies of then effect of A.D.P. on platelets, previously reported周 (Davey and Lander, 1964b). In the studies now reported, both blood and platelet radioactivities? were determined, as well as platelet counts.

HEPARIN ADMINISTRATION After obtaining severah్ pre-injection control blood samples, two subjects were given 5,000 units of heparin intravenously and four received 10,000 units. In five subjects, blood samples were collected every 15-30 minutes for two to three hours. In the remaining subject, whoo received 10,000 units of heparin, blood was sampled at minute intervals for 10 minutes. Clotting timeso were determined on almost all samples.

In all subjects heparin prolonged the clottingo time to more than 15 minutes for at least two hours, $N$ or until protamine or polybrene was given.

In the two subjects given 5,000 units of heparin no significant alteration in platelet count or radioactivity was observed. In the one given 10,000 units? in whom levels were followed for 10 minutes only no changes were detected.

In the other three subjects given 10,000 unitso some platelet counts within 30 minutes of injection were below the lower limit of normal (resting mean - 2 S.D.) as illustrated in Figs. 1 and 2. (At $30^{\circ}$ minutes, Fig. 1; at 10 and 15 minutes, Fig. 2; and at 


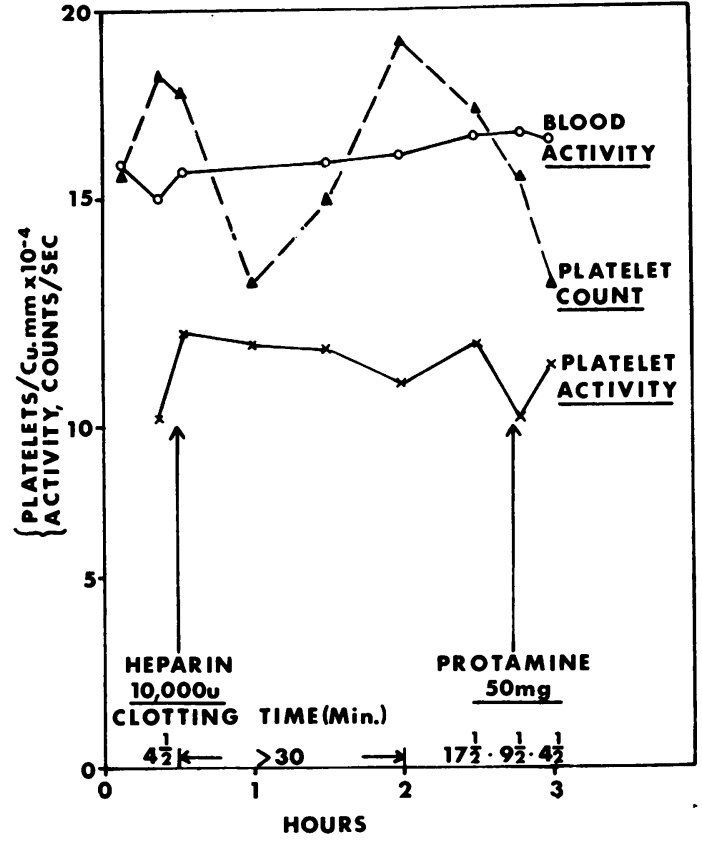

FIG. 1. Effects on platelet counts, whole blood and platelet radioactivity levels, and blood clotting times of the injection of 10,000 units of heparin (Boots) and its neutralization with protamine. five and 15 minutes in the other subject.) The lowest counts recorded were only $25-30 \%$ (approximately 3 S.D.) below the resting mean. All subsequent counts were within the normal range. In contrast, platelet radioactivity and whole blood radioactivity measurements did not alter significantly at any time, in any subject.

HEPARIN NEUTRALIZATION The action of heparin was neutralized by protamine sulphate in three subjects, and by hexadimethrine bromide (Polybrene) in two. Sufficient was injected to neutralize half the amount of heparin originally given, assuming 1,000 units to be neutralized by $10 \mathrm{mg}$. of either substance. Neutralization was confirmed by return of the clotting times to normal limits. Figures 1 and 2 show that no change in circulating radioactivity followed protamine injections, but platelet counts again fell transiently to slightly below resting limits. The same effect was observed when hexadimethrine bromide (Polybrene) was administered. Injection of protamine alone, while it prolonged the clotting time slightly, did not materially alter the platelet count or circulating radioactivity levels (Fig. 3 ).

PLATELET SURVIVAL The subsequent survival of ${ }^{51} \mathrm{Cr}$-labelled platelets in the subjects under study did not differ from that observed in normal, untreated subjects in this laboratory.

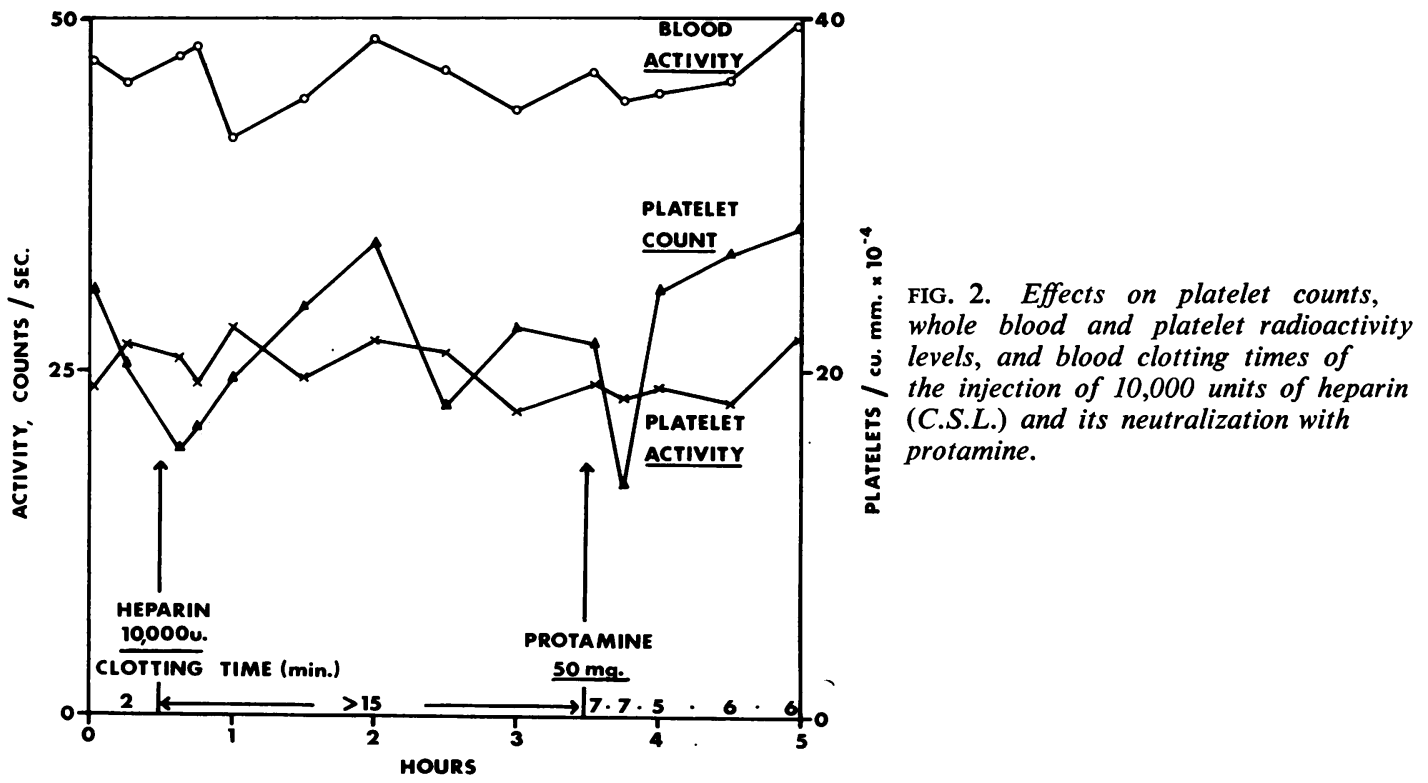




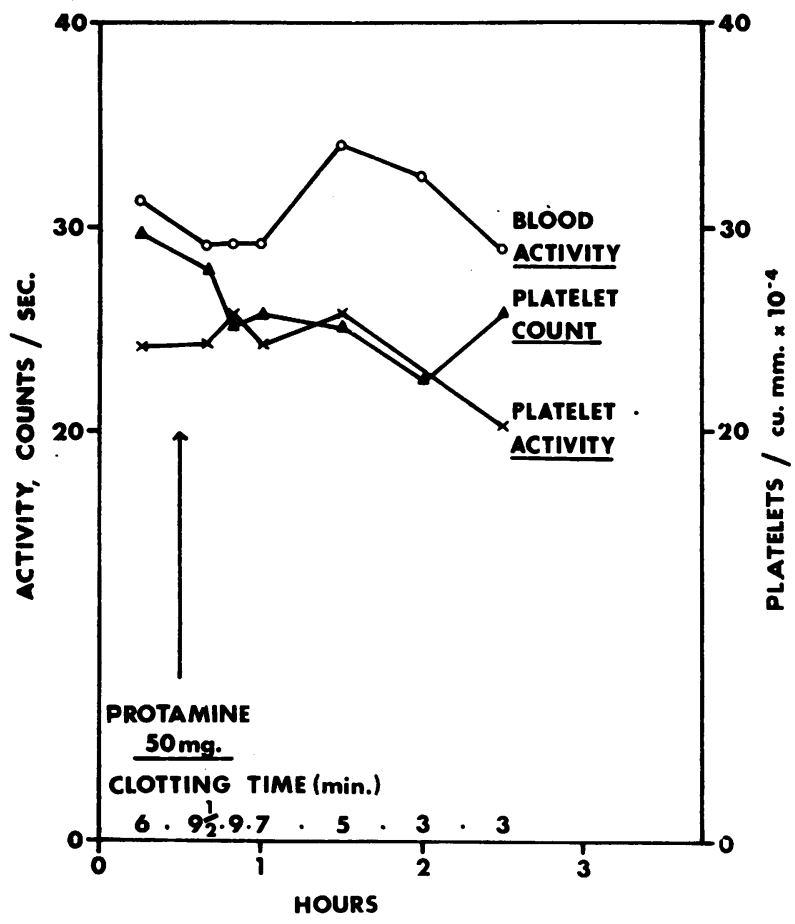

FIG. 3. Effects on platelet counts, whole blood and platelet radioactivity levels, and blood clotting times of the administration of $50 \mathrm{mg}$. of protamine to a subject who had received no heparin.

\section{DISCUSSION}

When both ${ }^{51} \mathrm{Cr}$-labelled and unlabelled platelets are present in the circulation of normal healthy individuals, the intravenous administration of heparin is sometimes followed by an apparent fall in platelet counts; but this change is not reflected in the circulating platelet radioactivity. This discrepancy would arise if labelled and unlabelled platelets differed in their reaction to injected heparin. However, there is no evidence to suggest that, except in the one to two hours immediately after infusion, labelled autologous platelets are distinguishable from other circulating platelets (Davey and Lander, 1964a), and it has been demonstrated that labelled platelets accurately reproduce the thrombocytopenic effects induced by such agents as adenosine diphosphate (Davey and Lander, 1964b), carbon particles, and bacterial endotoxin (Cohen, Braunwald, and Gardner, 1965). Therefore, had a real fall in circulating platelet levels occurred it should have been reflected in radioactivity measurements.

Wo believe, rather, that it is the apparent reduction of platelet counts which is the artefact and that no real in vivo change of platelet levels follows heparin administration. The effects of heparin in reducing platelet counts in vitro have often been reported (Copley and Robb, 1942a; Fidlar and Jaques, 1948; Perkins, Osborn and Gerbode, 1958). Clumping of platelets in heparinized blood in vitro has been shown to occur whether heparin was added in vivo or in vitro (Fidlar and Jaques, 1948). This would result in lower platelet counts being observed in blood samples taken from heparinized subjects when the circulating heparin concentration was highest. Clumps may not be seen in the samples taken for counting, as platelet aggregates may adhere even to non-wettable surfaces or other cells in the presence of small amounts of heparin (Mustard et al., 1963).

The same argument can be applied to the findings of Gollub and Ulin (1962). They gave only 4,000 units of heparin, but in four of their five studies, significant reductions in the platelet counts were observed within 30 minutes of heparin injection. The degree to which the counts fell (17 to $60 \%)$ was greater than that observed in the present studies after 10,000 units. As the clumping of platelets in heparinized blood is to some extent reversible (Fidlar and Jaques, 1948), and as the platelet counts were performed by Gollub and Ulin immediately after collection of blood, while ours were not carried out until the end of each study, this difference may be explicable in the same terms.

It is nevertheless possible that they observed a real thrombocytopenic effect, due to material other than heparin. They used three different American preparations of heparin, while we used Australian and English products. The presence of a common contaminant in the former, or of a different molecular species of heparin, might account for a different action, and deserves further investigation, if and when their findings can be confirmed by methods similar to those described in this paper.

We conclude from the experiments reported here, in conjunction with most published reports, that there is probably no in vivo thrombocytopenic effect of heparin itself in man.

We also failed to observe any significant thrombo- $N$ cytopenic effect of heparin antagonists. Although N such has been reported in man (Jaques, 1949; Preston, Hohf, and Trippel, 1956; Perkins et al., 1958), the studies we performed are insufficient to exclude that an effect occurs in circumstances $\stackrel{\Phi}{\sim}$ different from those of our experiments.

M.G.D. was a research fellow of the National Heart $\stackrel{\mathbb{D}}{\mathbb{D}}$ Foundation of Australia, whose financial support made $\mathbb{\mathbb { D }}$ the study possible.

We are particularly grateful to the men who volun-웅 
teered for these studies, to Professor H. N. Robson for his interest, and to Misses M. Hall and P. Chinner for their technical assistance.

\section{REFERENCES}

Björk, V. O. (1960). J. thorac. cardiovasc. Surg., 40, 237.

Bloom, A. L. (1961). Brit. med. J., 2, 16.

Borchgrevink, C. F. (1961). Acta med. scand., 170, 365.

Brecher, G., and Cronkite, E. P. (1950). J. appl. Physiol., 3, 365.

-, Schneiderman, M., and Cronkite, E. P. (1953). Amer. J. clin. Path., 23, 15.

Cohen, P., Braunwald, J., and Gardner, F. H. (1965). J. Lab. clin. Med., 66, 263.

Copley, A. L. (1948). Fed. Proc., 7, 22.

- , and Robb, T. P. (1942a). Amer. J. clin. Path., 12, 416.

- - (1942b). Ibid., 12, 563.

Davey, M. G., and Lander, H. (1963). Aust. J. exp. Biol. med. Sci., 41, 581 .

- - (1964a). Brit. J. Haemat., $10,94$.

__, - (19h4b). Nature (Lond.), 201, 1037.

Fidlar, E., and Jaques, L. B. (1948). J. Lab. clin. Med., 33, 1410.

von Francken, I., Johannson L., Olsson, P., and Zetterqvist, E. (1963). Lancet, 1, 70.

Gans, H., and Krivit, W. (1962). Ann. Surg., 155, 353.

Godal, H. C., and Abildgaard, U. (1963). Acta med. scand., 174, 311.
Gollub, S. (1964). Ann. N.Y. Acad. Sci., 115, 278.

-, and Ulin, A. W. (1962). J. Lab. clin. Med., 59, 430.

Hartmann, R. C. (1961). In Blood Platelets, edited by S. A. Johnson, R. W. Monto, J. W. Rebuck, and R. C. Horn, p. 499. Little, Brown Boston.

Hjort, P. F., Rapaport, S. I., and Jørgensen, L. (1964). Scand. J. Haemat., 1, 169.

Jaques, L. B. (1949). Brit. J. Pharmacol., 4, 135.

Johannson, S. A., Lundberg, A., and Sjöberg, H. E. (1960). Acta med. scand., 168, 165.

Moret, P. R., Feuardent, R., and Pattay, J. (1962). Hemostase, 2, 305.

Mustard, J. F., Murphy, E. A., Downie, H. G., and Rowsell, H. C. (1963). Brit. J. Haemat., 9, 548.

Perkins, H. A., Osborn, J. J., and Gerbode, F. (1958). Amer. J. clin. Path., 30, 397.

Preston, F. W., Hohf, R., and Trippel, O. (1956). Quart. Bull. Northw. Univ. med. Sch., 30, 138.

Quick, A. J., Shanberge, J. N., and Stefanini, M. (1948). J. Lab. clin. Med., 33, 1424.

Salzman, E. W. (1963). Transfusion (Philad.), 3, 274.

Sharp, A. A., Harding, N., and Ellis, H. (1965). Personal communication.

Verstraete, M., Amery, A., Vermylen, C., and Robyn, G. (1963). Lancet, 1, 446.

- Vermylen, C., Vermylen, J., and Vandenbroucke, J. (1965). Amer. J. Med., 38, 899.

Wensel, R. H., and Bigelow, W. G. (1959). Surgery, 45, 223. 